\title{
A rebuttal in defence of misinterpretation of the Galea et al. 2016 paper entitled "Pollution monitoring for sea salt aerosols and other anionic species at Hagar Qim Temples, Malta: a pilot study"
}

\author{
Matthew Grima ${ }^{1 *}$, Mario Galea ${ }^{2}$ and Roslyn DeBattista ${ }^{1}$
}

This commentary is being written as a scientific rebuttal to the interpretation made by Cassar et al. [1] with respect to the Galea et al. [2] study which was cited in detail within the said review. It is imperative to start by mentioning that the aims and purpose of the Galea et al. study were in the form of a pilot study targeting the identification of salt species, their quantity and deposition pattern, in both pre and post-sheltering situations. Several passages and arguments raised in the Galea et al. paper were not cited in their context by Cassar et al. but rather in a pre-disposed context with respect to whether or not this structure is good for a temple's protection. The Galea et al. study did not seek to address whether or not the tenting structure is beneficial, but merely to report findings on the deposition of aerosols as prescribed in the aims and selected methodology. In page 325, Galea et al. [2] went on to state that further research is needed and was hence recommended. No point was made on the decision to tent or not, simply because much more information is needed to address such which can only be gathered from further research which is what was in fact proposed in the said study.

The Galea et al. [2] study was criticized on all fronts; aims, methodology, results, discussions and even the conclusions reached, arguing at times to great lengths

*Correspondence: matthew.a.grima@gov.mt

${ }^{1}$ Diagnostic Science Laboratories, Heritage Malta, Kalkara, Malta

Full list of author information is available at the end of the article that severe misinterpretations were made and reported. A series of comments and rebuttals are thus being provided below to shed light on unfair reporting, scientific writing and comparisons with respect to the Galea et al. study.

On page 13 right column paragraph 1 Cassar et al. state that "the actual type of filter is not given" [1], contrary to the fact that on page 316 last paragraph of the Galea et al. study [2] this was provided. It is noteworthy to state that the filter is the same as quoted by the paper written by Torfs et al. [3]. Hence, the authors cannot understand how this detail was elaborated on by Cassar et al. when it was mentioned and even cited.

It is understood that changing scientific parameters between two sets of data in comparative analytics jeopardises the whole science being applied; but to argue that this happened in the Galea et al. study [2] is totally baseless and scientifically demeans the validity of results. Claims that sampling was carried out in different locations first appear in footnote 30 of the Cassar et al. paper [1], followed by repetitive citations in footnotes 32, 37 and 41. Sampling was carried out in the same location for the three campaigns. Target placement and orientation were determined through wind field surveys as quoted from Mandrioli [4] which was duly cited in the Galea et al. paper (p. 317) [2]. It must also be stressed that one of the Cassar et al. authors [1], who also happens to be the site curator, can verify that M. Galea had always insisted that the sample location of the stone bases which accommodated the samplers should never be moved. 
Another instance where Cassar et al. [1], criticized the Galea et al. paper [2] was in relation to the study's length. Why is the study called short and limited when a noteworthy journal published the pilot study following peer reviewing as declared in the title? It is meant to be short to validate methodology and capture a snapshot of the situation at hand. In fact the article is concluded by presenting ideas for further in-depth research, as is the norm in the scientific field.

Technically invalid scientific comparisons were also evident in the Cassar et al. [1] paper with resulting arguments being used as a foundation for their conclusions. A generic statement is made about how a rise in soluble ion presence was recorded between 1985 and 2005, right after presenting Galea et al. [2] salt fractions. The 1985 until 2005 studies are summarised by Cassar et al. in Table 1. By looking at these documents, one clearly comes to the realisation that the studies of Vannucci et al. [5] and Mandrioli et al. [6] cannot be compared to each other as well as to the Galea et al. study. Apart from the fact that the sampling positions were different, sampling methodologies varied such that, Vannucci et al. sampled superficially and by coring [5], Mandrioli by sampling fragments [7] and Galea et al. by aerosol deposition [2].

Furthermore, Cassar et al.s Table 1 presents anionic concentration ranges to compare the Vannucci et al. and Mandrioli studies [1]. This was a selective choice as both studies did not present ranges but rather site specific anion concentration reporting. More so, Cassar et al. did not take note of this site-specific detail as the Mandrioli anion concentrations reported in Table 1 pertain to restorations and mortars as per the table below, aside from the chloride and nitrate minima.

Therefore, this comparison cannot be used to substantiate that anion concentration increased from 1985 to 2005 and then present the idea to discount that rain can aid in washing out salts. It is pertinent to state here that Galea et al. [1] were criticised for hypothesising this when Mandrioli himself had hypothesised that "Under the shelter the impact of the marine aerosol on the stones will probably be reduced, but the salt deposited will not be removed by the rain action" ([6], p. 14).

These invalid scientific comparisons continued with respect to page 12, right column when Cassar et al. [1] compared the Cabello Briones and Viles [8] study to the Becherini et al. one [9]. This comparison is invalid since the length of the period within which the $\mathrm{NaCl}$ crystallization threshold assessments were executed is not the same. The Cabello Briones and Viles assessment was executed over 12 months ([8], Table 5, p. 10) while the Becherini et al. assessment was executed over 5 months ([9], Figure 6, p. 8). This renders the data set frequency and seasonal variation of the two studies incomparable and therefore one cannot draw conclusions to state that conditions are possibly getting better, as Cassar et al. did.

Excessive criticism towards Galea et al. [2] was also made in relation to reporting the presence of phosphate ions. Cassar et al. reported that the herbicide glyphosate had a big impact in terms of phosphate ion presence [1]. The authors ended by highlighting that knowing that the phosphate source is glyphosate is important since Galea et al. drew most conclusions on phosphate deposition [1]. A negative tag on the Galea et al. paper is placed with reason being not knowing what the source was. Galea et al. only intended via their aims to report findings and not necessarily sources. However, due to extreme soil accumulation it was reported that the phosphate fraction was originating from the soil, something which Cassar et al. actually corroborate. In this regard the Galea et al. study even recorded a man-made event in terms of glyphosate presence on site. Upon discovering that glyphosate was used on top of the Galea et al. findings, Cassar et al. reported how glyphosate dissolves in soil but no mention

Table 1 A table relating the Mandrioli anion concentration [4] reported by Cassar et al. [1] to the Mandrioli sampling labels and descriptions [4]

\begin{tabular}{|c|c|c|}
\hline Anion & $\begin{array}{l}\text { As cited by Cassar et al. [1] } \\
\text { from Mandrioli et al. [4] Table 3.6.4 } \\
\text { (ppm) }\end{array}$ & As described by Mandrioli in sampling Table 3.6.1 [4] \\
\hline Chlorides minima & 1863 & HQT6: Room 5. On the Ground. Original_fragment of Globigerina Limestone \\
\hline Chlorides maxmima & 12,363 & HQT2: Room 6. Same location of HQT1E. Left side of block — fragments of mortar \\
\hline Sulfates minima & 1187 & $\begin{array}{l}\text { HQT1D: Room 6. Sector } \beta .1920 \text { restoration work. Pilaster, } 150 \mathrm{~cm} \text { from ground } \\
\text { level_fragment of globigerina limestone }\end{array}$ \\
\hline Sulfates maxmima & 84,063 & $\begin{array}{l}\text { HQT1B: Room 6. Sector } \beta .1920 \text { restoration work. Pilaster, } 60 \mathrm{~cm} \text { from ground } \\
\text { level_fragment of globigerina limestone }\end{array}$ \\
\hline Nitrates minima & 252 & HQT6: Room 5. On the Ground. Original_fragment of Globigerina Limestone \\
\hline Nitrates maxmima & 8587 & HQT2: Room 6. Same location of HQT1E. Left side of block_fragments of mortar \\
\hline
\end{tabular}


on the possible physical harm it may cause to the stone surface.

One final point which merits attention relates to Cassar et al.s page 8 reference highlighting the aggressive environments to data sensors as a challenge for optimal data capture [1]. While they state that sensors broke down due to the accumulation of dust and salts on them [1], the Galea et al. study [2] was severely criticized for mentioning that there is the same exact risk of accumulation of dust and salt on the megaliths due to greater deposition as referenced through Gomez Bolea et al. [10]. Some of these sensors were below the tent and situated on the megaliths themselves. Hence, one must ask how can the accumulation of dust and salt that broke down these sensors in the space of a few months have absolutely no effect on the stone itself? It is pertinent to state that the criticism levelled at Galea et al. is quite surprising since the aspect of soil, dust and salt accumulation was cited by Becherini et al. [9] and reported duly in its context under a subheading of "Risks to temples: past and present" [9]. However, it was surprising since Galea et al. were severely criticised for the same words when cited by Cassar et al. [1], when the corresponding author of the latter co-authored in the former.

\section{Conclusion}

Although the overarching objective of the Galea et al. study [2] was to formulate and pilot a methodology whereby the outcome is expected to contribute to the ultimate aim of arriving at a scientific evaluation of the effects created by the tent, the study was cited totally out of context and unfairly criticised. To evaluate the effects of a structure, the different niche areas being researched have to be evaluated to ultimately conclude on its effectiveness. But to do this at such an early stage, has rendered all cited studies, including the Galea et al. paper into an undesired context of whether to tent or not to tent. Such rash remarks create an aura of scientific bias which risk being the departure point for research to come, especially when we are still half way through researching the effects of the tenting efficacy. More worryingly is the manner with which these conclusions where reached since misinformation was generated by leaving key facts out when citing the Galea et al. paper and invalidating scientific comparisons by comparing studies to each other when these could never be compared due to variables being different.
Authors' contributions

All authors read and approved the final manuscript.

Author details

${ }^{1}$ Diagnostic Science Laboratories, Heritage Malta, Kalkara, Malta. ${ }^{2}$ Preventive Conservation Unit, Heritage Malta, Kalkara, Malta.

\section{Competing interests}

The authors declare that they have no competing interests.

\section{Publisher's Note}

Springer Nature remains neutral with regard to jurisdictional claims in published maps and institutional affiliations.

Received: 19 September 2018 Accepted: 27 September 2018

Published online: 03 December 2018

\section{References}

1. Cassar J, Cefai S, Grima R, Stroud K. Sheltering archaeological sites in Malta: lessons learnt. Herit Sci. 2018:6(36):1-18.

2. Galea M, DeBattista R, Grima M, Maccarelli L, Borg R, Zerafa C. Pollution monitoring for sea salt aerosols and other anionic species at Hagar QimTemples, Malta: a pilot study. Conserv Manag Archaeol Sites. 2015;17(4):315-26.

3. Torfs K, Van Grieken R, Cassar J. Monitoring of environmental parameters to explain stone deterioration: Church of Sta Marija Ta'Cwerra, Malta. In: Proceedings of the 8th international congress on deterioration and conservation of stone. Berlin: Moller Druck. 1996; p. 265-71.

4. Mandrioli P. Environmental Monitoring at Hagar Qim and Mnajdra Temples. Unpublished Fourth Quarterly (Final) Report for Tender CT 2592/04. Consiglio Nazionale delle Ricerche, Istituto di Scienze dell'Atmosfera e del Clima (CNR-ISAC); 2006a. p. 11-20, 31, 39; unpublished report.

5. Vannucci S, Alessandrini G, Cassar J, Tampone G, Vannucci ML. I Templi Megalitici Preistorici delle Isole Maltesi: cause e processi di degradazione del Globigerina Limestone. In: Fassina V, Ott H, Zezza F, editors. Conservation of monuments in the Mediterranean Basin. Proceedings of the 3rd international symposium. Venice: Soprintendenza ai Beni Artistici e Storici di Venezia; 1994. p. 555-65.

6. Mandrioli P. Environmental Monitoring at Hagar Qim and Mnajdra Temples. Unpublished Results and recommendations on the microenvironmental impact of the shelters for the Temples for Tender CT 2592/04. Consiglio Nazionale delle Ricerche, Istituto di Scienze dell'Atmosfera e del Clima (CNR-ISAC); 2006b.

7. Mandrioli P. Environmental Monitoring at Hagar Qim and Mnajdra Temples. Unpublished Interim Report for Tender CT 2592/04. Consiglio Nazionale delle Ricerche, Istituto di Scienze dell'Atmosfera e del Clima (CNR-ISAC). 2006c; p. 61; unpublished report.

8. Cabello-Briones C, Viles HA. Evaluating the effects of open shelters on limestone deterioration at archaeological sites in different climatic locations. Int J Archit Herit. 2017;11(6):816-28.

9. Becherini F, Cassar J, Galea M, Bernardi A. Evaluation of the shelters over the prehistoric Megalithic Temples of Malta: environmental considerations. Environ Earth Sci. 2016;75(1079):1-13.

10. Gomez-Bolea A, Llop Vallverdu E, Alvaro Martin I, Rosines N. Environmental Monitoring at Hagar Qim and Mnajdra Temlpes. Unpublished Final Report to Heritage Malta; October 2008; 2008. 